\title{
Education in the pandemic: questions about teaching work, curriculum and remote teaching
}

\section{A educação na pandemia: indagações sobre trabalho docente, currículo e ensino remoto}

\section{La educación en la pandémica: preguntas sobre el trabajo docente, currículos y enseñanza remota}

\author{
Claudio Pinto Nunes ${ }^{1}$ iD, Daniele Farias Freire Raic ${ }^{2}$ iD, Ester Maria de Figueiredo Souza ${ }^{1}$ iD \\ ${ }^{1}$ Universidade Estadual do Sudoeste da Bahia, Vitória da Conquista, Bahia, Brasil. \\ 2 Universidade Estadual do Sudoeste da Bahia, Jequié, Bahia, Brasil.
}

\section{Autor correspondente:}

Claudio Pinto Nunes

Email: claudionunesba@hotmail.com

Como citar: Nunes, C. P., Raic, D. F. F., \& Souza, E. M. F. (2021). Education in the pandemic: questions about teaching work, curriculum and remote teaching. Revista Tempos e Espaços em Educação, 14(33), e16047.

http://dx.doi.org/10.20952/revtee.v14i33.16047

\section{ABSTRACT}

This work presents problems in the field of teacher education in the context of the COVID-19 pandemic. Therefore, it is structured into three topics that approaches teaching work, curriculum and remote teaching. We took as a motto for writing this text, our participation in events called the Pedagogical Journey, when we confronted readings and experiences by teachers participating in these events. It emphasizes the need to appropriate the notions of human education, work and remote teaching so that the pandemic event is recognized as a determining context for the provision of education in a format in the circumstances due to physical distance. As alternatives to face this scenario, addressing the possibilities of remote education and training, both under the framework of the student and the teacher, emphasizing the material conditions for their offer by the educational management bodies. We gather guidelines to corroborate that the right to education in the pandemic is dependent on socio-digital inclusion and pedagogical planning that is guided by the adoption of remote learning in a collaborative way for decision-making.

Keywords: COVID-19. Curriculum. Human formation. Remote teaching. Teaching work.

\section{RESUMO}

Este trabalho apresenta problematizações no campo da formação docente no contexto da pandemia da COVID-19. Para tanto, estrutura-se em três tópicos que abordam trabalho docente, currículo e ensino remoto. Tomamos como mote para a escrita deste texto, a nossa participação em eventos denominados de Jornada Pedagógica, quando confrontamos leituras e as experiências 
pelos docentes participantes desses eventos. Enfatiza-se a necessidade de se apropriar das noções de formação humana, trabalho e ensino remoto para que o evento da pandemia seja reconhecido como contexto determinante para a oferta da educação em formato nas circunstâncias pelo distanciamento físico. Como alternativas para o enfrentamento desse cenário, abordando-se as possibilidades do ensino remoto e da formação, tanto sob o enquadre do estudante, como do docente, ressaltando as condições materiais para a sua oferta pelos órgãos gestores da educação. Reunimos orientações para corroborar que, o direito à educação na pandemia é dependente da inclusão sociodigital e do planejamento pedagógico que se orienta pela adoção do ensino remoto em regime colaborativo para tomada de decisão.

Palavras-chave: COVID-19. Currículo. Ensino remoto. Formação humana. Trabalho docente.

\section{RESUMEN}

Este trabajo presenta problemas en el campo de la formación docente en el contexto de la pandemia COVID-19. Para tanto, se estructura en tres temas que abordan el trabajo docente, el currículo y la enseñanza remota. Tomamos como lema para la redacción de este texto, nuestra participación en eventos denominados Jornada Pedagógica, cuando comparamos lecturas y experiencias de los docentes que participan en estos eventos. Destaca la necesidad de apropiarse de las nociones de educación humana, trabajo y enseñanza remota para que el evento pandémico sea reconocido como un contexto determinante para la provisión de educación en un formato en las circunstancias de la distancia física. Como alternativas para afrontar este escenario, abordar las posibilidades de la educación y formación remota, tanto en el marco del alumno como del docente, destacando las condiciones materiales para su oferta por parte de los órganos de gestión educativa. Recopilamos pautas para corroborar que el derecho a la educación en la pandemia depende de la inclusión socio-digital y la planificación pedagógica que se rija por la adopción de la enseñanza remota de forma colaborativa para la toma de decisiones.

Palabras clave: COVID-19. Currículo. Enseñanza remota. Formación humana. Trabajo docente.

\section{INTRODUÇÃO}

Este trabalho, no intuito de ampliar a problematização acerca do direito à educação nos tempos da Pandemia da COVID-19, interroga sobre as possíveis modalizações dos temas da formação humana, conhecimento escolar e aprendizagem, no contexto não presencial das escolas, em decorrência do isolamento social e da suspensão das aulas e demais atividades nos estabelecimentos de ensino.

Não só a vida social foi impactada, mas todo o cotidiano escolar, compreendendo a escola como parte da estrutura social. Há uma ênfase na suspensão das aulas respaldadas por atos normativos e decretos, contudo, não só as aulas foram suspensas, mas está em suspensão o próprio direito à educação, à aprendizagem e à formação, antes as condições de precariedade de inclusão sociodigital, principalmente em países com a estratificação social e concentração de renda como o Brasil.

Assim, a questão central que orienta nossa escrita, parte de motivação de live ${ }^{1}$ realizada como evento de uma Jornada Pedagógica para possibilitar a organização das atividades escolares no cenário da pandemia da Covid-19, momento que nos despertou para sintetizar as provocações, associando-as ao que tematizamos, como palestrantes, ao direito à educação e preservação da vida, confluindo para o trio conceitual de formação humana, currículo e ensino remoto

Quais as possibilidades para a oferta do ensino, no intuito de minimizar prejuízos advindos da pandemia, ante a suspensão de aula? Como, a escola, perspectiva a oferta da educação, como direito humano, para atender as necessidades de aprendizagem dos estudantes e a formação

\footnotetext{
${ }^{1}$ https://www.youtube.com/watch?v=gHB-rnQogK0\&t=9309s
} 
docente para enfrentar os desafios impostos? Nesse intuito, este texto se estrutura em tópicos que tratam do contexto socioeducacional na pandemia da Covid-19; com exposição sobre regulamentação de órgãos o direito à aprendizagem a partir do modelo ensino remoto e/ou híbrido adotado como possibilidade pedagógica para vínculo do estudante com a ambiência escolar; a formação e o currículo, entendido como linguagem cujas práticas discursivas produzem sentidos e significados que muitas vezes o reduz a um conjunto de disciplinas e objetivos de aprendizagens essenciais à aprendizagem dos estudantes escolarizados e as exigências relativas ao trabalho docente. Nosso intuito foi o de refletir e socializar esse debate, ainda em curso, após mais de um ano de descontinuidade ou suspensão das aulas nos estabelecimentos de ensino.

\section{CONTEXTO SOCIOEDUCACIONAL NA PANDEMIA DA COVID-19}

A Organização Mundial da Saúde (OMS) declarou como Emergência de Saúde Pública de Importância Internacional (ESPII), em 30 de Janeiro de 2020, o surto da infecção humana pelo Coronavírus (COVID-19). JÁ no mês de março do mesmo ano, foi confirmada a contaminação comunitária em todos os Continentes, o que, segundo critério epidemiológico, caracteriza-se como pandemia e, nesse contexto, as regras de mitigação e salvaguarda da vida passam pelas medidas de distanciamento físico, distanciamento social, testagem até a imunização da população.

No Brasil, o Ministério da Saúde corroborando com a declaração da OMS, editou Portaria no 188/GM/MS e os órgãos federativos vem editando decretos e adotando e acompanhando medidas que vão do lockdown ao distanciamento social. Assim, no âmbito educacional, o Ministério da Educação, em março de 2020, por meio da Portaria no 343, orientou acerca da oferta de aulas presenciais, indicando a sua substituição por meios digitais, para a Educação Superior e, para a Educação Básica, o Conselho Nacional de Educação (CNE), estende e elucida essa compreensão para todos os níveis, etapas e modalidades do Sistema Nacional de Educação, considerando a necessidade de reorganizar o calendário letivo, a carga horária, a natureza das atividades pedagógicas e curriculares que, em decorrência das necessárias ações e medidas de prevenção da Covid-19, impactaram o cotidiano dos estabelecimentos de ensino.

Como exemplo sequencial de medidas em todo território nacional, a partir do posicionamento e regulamentos dos órgãos normativos no âmbito da educação, no estado da Bahia, o Conselho Estadual de Educação, ainda em março, mediante resolução ${ }^{2} \mathrm{CNE} / \mathrm{n}$ - Resolução CEE N.ㅇ 27, de 25 de março de 2020 publicou sua primeira resolução atinente à prerrogativa de validar o direito à educação na pandemia. Essa resolução, em seu parecer CEE 53/2020 atenta que

[...] o campo dos currículos com o uso de mecanismos de EaD, educação on-line, exige um desenho didático para ambientes virtuais de ensino-aprendizagem, que deve levar em conta a desigualdade de acesso, a formação docente para uso dessas tecnologias, a mediação com públicos heterogêneos de estudantes, a cultura escolar e seus desdobramentos para a assistência às necessidades dos estudantes, dentre outras especificidades (CEE 53/2020, p/2).

Como desdobramento, novas normativas foram editadas, para orientar às instituições integrantes do Sistema Estadual de Ensino sobre o desenvolvimento de atividades curriculares, possibilitando o que se denominou, no âmbito interno/Estado da Bahia, como regime especial de ensino, facultando às instituições a qualquer momento, enquanto perdurar a situação de emergência, a adesão ao regime especial.

Por condições materiais que envolvem atendimento da infraestrutura de equipamentos até formação docente, esse regime especial foi adotado, em larga escala, pelas instituições privadas e, com menos aderência aos municípios. Essa adesão em parte ou total, além de gerou/revelou as

\footnotetext{
${ }^{2}$ http://www.conselhodeeducacao.ba.gov.br/arquivos/File/homologadares272020.pdf
} 
disparidades sociais, as desigualdades de acesso e inclusão sociodigital, repercurtindo no direito à educação e no atendimento do planejamento pedagógico traçado pelas escolas do segmento público.

Assim, após um ano de suspensão de aulas no, a realidade se mostrou cada vez mais excludente com os estudantes das escolas públicas, vez que um breve levantamento realizado, as escolas da rede privada de ensino conseguiram reorganizar seus calendários e manter o fluxo de atividades pedagógicas não presenciais. Há inúmeras experiências e diversas situações de oferta das atividades escolares na pandemia. Um mapeamento dessa situação encontra-se no site ${ }^{3}$ da CONSED e, no Estado da Bahia, a União dos Dirigentes Municipais da Educação ${ }^{4}$, no âmbito municipal, informa que, de em mapeamento com os 407 municípios baianos, do total de 417, 60 municípios não realizaram atividades remotas em 2020 e desses 60, 57 sinalizaram que finalizariam o ano em dezembro de 2020, e os demais com carga horária diferenciada.

Ante esse cenário, docentes, estudantes e famílias defrontaram-se com expressões como ensino remoto, ensino híbrido, ensino não-presencial - o que abordaremos mais adiante neste artigo - como possibilidades para garantir o vínculo do estudante com a escola e a ambiência pedagógica no domicílio, a partir da ação docente neste novo arranjo didático; o que continuaremos a abordar tópicos seguintes.

\section{TRABALHO DOCENTE NA PANDEMIA}

Pensar o trabalho docente durante a pandemia do Covid-19 requerer situar a atividade profissional do professor em três momentos, a saber: situação pré pandêmica; pandêmica e perspectivas para o pós-pandemia.

Uma conquista importante deve ser registrada na primeira década dos anos 2000 quando houve o professor passou a vivenciar a situação favorável (ou ao menos esperançosa) proveniente da definição do Piso Salarial Profissional Nacional (PSPN), decorrente da, com a definição da Lei n.⒒738 (Brasil, 2008), conforme se registra em diferentes estudos (Teixeira \& Nunes, 2019a; 2019b; 2019c; 2016).

O estabelecimento do Plano Nacional de Educação - PNE (Brasil, 2014), com definição de vinte metas e 254 estratégias, demarcou um panorama positivo que partia das situações presentes com perspectivas claras de futuro. O PNE tem como marco mais importante o fato de ter sido posto como política de Estado que tinha em seu cerne a articulação entre os entes federados, no sentido de promover, regular e avaliar a educação, considerando as especificidades de cada ente, mas garantindo - ou ao menos, perspectivando - uma unidade do direito à aprendizagem aos brasileiros em idade escolar ou mesmo após a idade regularmente definida para a educação básica.

À União cabe organizar o sistema federal de ensino, financiar as instituições de ensino federais e exercer, em matéria educacional, função redistributiva e supletiva, para garantir equalização de oportunidades educacionais e padrão mínimo de qualidade do ensino mediante assistência técnica e financeira aos estados, ao Distrito Federal e aos municípios. Os municípios devem atuar prioritariamente no ensino fundamental e na educação infantil; os estados e o Distrito Federal, prioritariamente nos ensinos fundamental e médio (Brasil, 1988, art. 211, §§ 1으, 2으 e 3ㅇ).

Entretanto, tão logo entrou em vigor o PNE de 2014-2024, o Brasil passa a viver fortíssima instabilidade política que termina no impeachement da presidenta Dilma Rousseff, em 2016. As antigas forças político-partidárias que comandaram o poder central no Brasil não aceitaram as mudanças implementadas a partir de um governo de vertente mais popular e alinhado mais à esquerda que vinha desde 2003.

\footnotetext{
${ }^{3}$ https://consed.info/ensinoremoto/

${ }^{4}$ https://undimebahia.com.br/site/2021/02/08/4915/
} 
Várias análises (Saviani, 2017; Antunes, 2017; Ribeiro; Silva; Cardoso \& Nunes, 2018; Calazans \& Nunes, 2018; Silva; Brito \& Nunes, 2019) registram a inquietação e as diferentes articulações políticas encabeçadas pelas autoridades políticas mais alinhadas à direita, com perfil neoliberal, com o intuito de colocar fim ao mantado presidencial liderado pelos partidos de bandeira mais popular.

Após o impeachement da presidenta Dilma Rousseff, como relatado por Silva, Brito e Nunes (2019), uma série de medidas foram lançadas contra a educação pública brasileira. Exemplos disso podem ser citados o corte de verbas para a Educação Superior, a Reforma do Ensino Médio, o crescimento do movimento Escola sem Partido, a Emenda Constitucional (EC) n.o 95/2016, entre outras. A Emenda Constitucional 95/2016 (Brasil, 2016) altera o Ato das Disposições Constitucionais Transitórias, para instituir o Novo Regime Fiscal, e dá outras providências e afeta diretamente o cumprimento das metas do Plano Nacional de Educação 2014-2024. A referida Emenda Constitucional congela os gastos com a educação e outros setores por 20 anos, o que corresponde ao período que se estende até 2036.

O congelamento de gastos em educação atinge frontalmente a na meta 20 do PNE, que prevê "Ampliar o investimento público em Educação pública de forma a atingir, no mínimo, o patamar de 7\% do Produto Interno Bruto (PIB) do País no 50 ano de vigência desta Lei e, no mínimo, o equivalente a $10 \%$ do PIB ao final do decênio" (Brasil, 2014). Ao se inviabilizar o cumprimento da meta 20, inviabilizam-se todas as demais metas, pois o PNE é uma política pública. Uma política pública, sem clara destinação de recursos públicos, não é política; é, antes disso, discurso ou mesmo a falsificação de uma "pseudo-boa-vontade" que não encontrará condições de levar a cabo o cumprimento das metas previstas.

Para se ter mais um exemplo de como o congelamentos de gastos atinge o PNE, basta de observa a meta 17 que prevê até o ano de 2020 a equiparação salarial de 100\% para os profissionais do magistério em relação aos demais trabalhadores com a mesma escolaridade. Mais um meta inviabilizada, tendo em vista a impossibilidade de destinação de recursos suficientes para acompanhar a necessidade de aumento salarial. Ao mesmo tempo, a impossibilidade de cumprimento da meta 17 do PNE põe por terra o Piso Salarial Nacional, tendo em vista que esta política demanda o aumento anual; nesse contexto, dificilmente os gestores dos entes federados terão condição para aumentar o salário dos professores e dos demais profissionais da educação.

Na sequência do cenário político, no que tange à educação no contexto pré-pandemia, é preciso registrar que a disputa eleitoral de 2018 foi marcado por todos esses debates provenientes do movimento antes e pós impeachement de 2016. O que se seguiram, como governo de Michel Temer, foram a continuidade e o aprimoramento dos ataques à educação, tanto no sentido ideológico como nos cortes ou diminuição de recursos destinados à educação nos níveis básico, superior e pós-graduado.

O mandato do presidente Jair Bolsonaro, eleito em 2018, com perfil político de extrema e com forte apoio de grupos sociais conservadores, com forte apoio dos veículos de comunicação de massa, aprofunda a política de cortes financeiros destinados a diferentes setores da sociedade, notadamente o setor educacional.

É nesse contexto que se deflagra o processo de pandemia do Covid-19. Conjuntura marcada, ao mesmo tempo, por um fenômeno impensável de negação ao conhecimento científico; movimento encabeçado pelo próprio presidente da República.

A pandemia da Covid-19 impôs a necessidade do isolamento social. Nesse sentido, a categoria profissional dos professores passou a trabalhar no ambiente doméstico. Esse trabalho foi, inicialmente, marcado por pensar estratégias para dar continuidade à escolarização e, com isso, garantir o direito à aprendizagem da sociedade. Posteriormente, após definição de algumas formas pensadas para dar continuidade ao processo de escolarização, os professores passaram a planejar 
e desenvolver aulas por meio daquilo que ficou conhecido como ensino remoto emergencial (ERE) e atinge a todos os níveis de formação humana (Souza \& Ferrreira, 2020).

A pandemia imprimiu uma conjunta de incertezas. A inexistência de uma vacina para combater o coronavírus (SARS-CoV-2), a falta de políticas nacionais de efetivo enfrentamento da pandemia, entre tantas outros episódios ocorridos durante o ano de 2020 e ainda em 2021, são marcas de que a luta por continuidade da instituição escola - e tudo que disso decorre - é uma necessidade imposta pela e para a própria sociedade.

Vista por esse prisma, a escola, como garantia do direito à aprendizagem, demanda, de um lado, condições de trabalho docente para o ensino remoto emergencial e, ao mesmo tempo, formação de professores, aqui entendida como forma de desenvolvimento profissional para o enfrentamento das demandas das formas de ensinar e dos modos de aprender na pandemia.

Compreendemos que essas necessidades (aprendizagem pelos estudantes e formação para os professores) são, na verdade, exigência da própria vida em comunidade e, portanto, demandas sociais. Assim compreendidos, formação docente e ensino-aprendizagem de qualidade são um direito do cidadão. Por um lado, a formação dos professores oportuniza uma escolarização (o ensino) com melhores condições para que ocorra a aprendizagem; por outro lado, níveis mais elevados e mais qualificados de aprendizagem pelos estudantes não são direitos desses dois sujeitos (professores e alunos). Um boa formação docente e um bom ensino-aprendizado são não para o professor e/ou para o aluno. Antes de tudo, a grande beneficiária da confluência do binômio formação de professores e qualidade do ensino é a sociedade. Esta se utiliza dos que ensinam e dos que aprendem para contar com cidadãos com qualificação para compor o que é a sociedade de cada tempo.

Nessa perspectiva, a Constituição Federal (Brasil, 1988), ao estabelecer no Art. 205 que "a educação como direito de todos e dever do Estado e da família" e no Art. e 206 que "o ensino será ministrado com base, dentre outros, no princípio da igualdade de condições para o acesso e permanência na escola", afirma o que há muito vinha sendo pauta de luta.

Como legislação que tem a prerrogativa de dar especificidade para a área da Educação sobre que estabelece a Carta Magna, a LDBEN (Brasil, 1996) em seu Art. 20 reafirma para que a CF seja considerada como elemento específico na área de educação o princípio constitucional de que a educação dever da família e do Estado, conjuntamente, embora cada instância (instituição) tenha de assumir sua parte da obrigatoriedade desse direito.

Postos esses preceitos legais (Brasil, 1988; 1996), para que não fiquem esquecidos ou fora do debate. que a legalidade que arregimenta nossas ações no contexto da normalidade também precisa estar no centro da pauta também no contexto da pandemia do Covid-19.

Importante registrar que a Emenda Constitucional 95/2016, que limita gastos dos estados e municípios, termina por diminuir as condições de esses entres federados atuarem em várias frentes que constituem o poder público, incluindo a Educação. Entretanto, embora haja uma limitação da ação - ou o cerceamento de muitas ações -, o Estado não limitou o seu perfil regulador. Em outras palavras, o Estado diminui sua ação como provedor e mas se mantém como regulador na medida que mantém se mantém normatizando as ações de cada setor público e, igualmente, não abre mão do poder definir as regras de avaliação. Exemplos disso são o Índice de Desenvolvimento da Educação (IDEB), o Exame Nacional do Ensino Médio (ENEM)postos como instrumentos de avaliação da educação básica.

$\mathrm{Na}$ educação superior, o poder regular do Estados se manifesta pelo Exame Nacional Exame Nacional de Desempenho dos Estudantes (Enade), que integra o Sistema Nacional de Avaliação da Educação Superior (Sinaes), que inclui, ainda, a Avaliação de cursos de graduação e a Avaliação que cada instituição tem a tarefa de realizar. O Enade avalia o rendimento dos concluintes dos cursos de graduação em relação aos conteúdos programáticos previstos nas diretrizes curriculares dos cursos, o desenvolvimento de competências e habilidades necessárias ao aprofundamento da 
formação geral e profissional, e o nível de atualização dos estudantes com relação à realidade brasileira e mundial.

Em nível de formação pós-graduada, o Estado regulador se expressa pelo Sistema Nacional de Pós-Graduação (SNPG), os Planos Nacionais de Pós-Graduação (PNPG) e Diretoria de Avaliação (DAV) da Coordenação de Aperfeiçoamento de Pessoal de Nível Superior (CAPES).

Nos diferentes níveis de atuação profissional, os profissionais da educação terminam por perder a autonomia sobre seu trabalho. A avaliação realizada pelos professores é posta de lado para darem lugar à avalição nacional, externa e desvinculada das realidades locais.

$\mathrm{Na}$ contramão do poder regulador do Estado estão os profissionais com dupla jornada de trabalho, falta de condições para se dedicarem a uma única profissão, tendo de se desdobrarem em face dos salários com valores muito abaixo das necessidades de pessoais e familiares. Além disso, há que se destacar as condições desfavoráveis para estabelecerem na carreira na constituição de um perfil científico-profissional, pois têm de dividir tempo de atuação na área de educação com atuação em outras frentes de trabalho (formal ou informal) para garantirem suas necessidades humanas essenciais.

No contexto da pandemia do COVID-19, é preciso registrar que, ao transportar toda a atividade profissional para dentro de suas próprias casas (antes eram parte na escola e parte em casa), o que se observou foi o acúmulo ou sobreposição de demandas oriundas do exercício profissional e do ambiente doméstico que passa a se configurar como um único contexto.

Importante destacar, ainda, que muitos dos professores são, também, pais/mães de alunos. Nesse sentido, também acumulam a função de acompanhar a agenda de estudos e de vida dos filhos. Esse registro se faz necessário tendo em vista que a escola sempre reivindicou a participação efetiva dos pais e responsáveis pelos estudantes no que concerne ao andamento da qualidade da escolarização ofertada pelas instituições educativas e, portanto, o direito efetivo à aprendizagem (Souza \& Ferriera, 2021) e a constante melhoria da escola e do ensino-aprendizado (Nunes \& Oliveira, 2017; Nunes, 2019).

O contexto que se expecta para o pós-pandemia do COVID-19 é incerto ou, ao menos, duvidoso. O cenário segue igual e cada vez mais agravado, pois o negacionismo da Ciência, os constantes ataques à Educação se mantém. Igualmente, tudo isso segue com o apoio de segmentos expressivos da sociedade, como algumas entidades religiosas, alguns grupos midiáticos.

\section{PROBLEMATIZANDO O CURRÍCULO E SUAS PRÁTICAS NA AMBIÊNCIA DOMICILIAR}

Como dissemos até aqui, a pandemia trouxe para nós, docentes, familiares e estudantes novas paisagens para o trabalho escolar. Em um dos nossos estudos anteriores (Raic \& Sá, 2021, p. 29), produzido no início da pandemia, anunciamos a emergência de um pós-normal em educação, não como um "novo-normal", como temos visto sendo enunciado aqui e acolá, tampouco como uma sequência temporal do que vem depois do normal, mas "tão somente [como] um exercício na direção de repensarmos nossos modos de produzir e habitar em novos territórios". Pensar em um pós-normal na educação é um esforço em perceber os fluxos intensos e imponderáveis nos quais a pandemia nos lançou, colocando-nos em importantes movimentos curriculares decorrentes do deslocamento das atividades escolares - antes desenvolvidas no espaço físico da escola - para o domicílio dos estudantes. Esse deslocamento, a nosso ver, tanto tem provocado a desconstrução das práticas curriculares que, até então, se mantinham, na maioria das vezes irretocáveis, quanto tem nos lançado a um horizonte de incertezas e instabilidades, o qual não podemos desprezar.

Quando somos convidados a pensar na escola, o que vem a nossa mente? De modo apressado, imaginamos salas de aulas com suas carteiras enfileiradas (ou não), estudantes realizando atividades, professores à frente das salas ministrando aulas, cantinas, refeitórios lotados, barulhos de diversas naturezas ou mesmo um silêncio fulcral requerido muitas vezes pelo trabalho pedagógico. Cada um de nós tem uma imagem de escola, construída em nossas vivências e 
experiências, seja dos tempos de estudantes, seja da prática profissional. E, embora não tenhamos a intenção de recorrer a uma representação de escola, não queremos perder de vista que as sociedades modernas assim a instituiu. Nesse "modelo" de escola, o currículo aparece quase sempre como um conjunto de disciplinas e de objetivos de aprendizagens comprometidos com lógicas cognitivistas, fortalecendo a ideia de conteúdos escolares como aqueles que são produzidos pelos diferentes campos de conhecimentos a serem ensinados progressivamente conforme o "nível de compreensão" dos escolares. Esse conhecimento ensinado na escola muitas vezes se distancia do conhecimento que é produzido pelas comunidades acadêmicas, literárias, artísticas, filosóficas do que é efetivamente ensinado na escola. Geralmente são conhecimentos tidos como verdadeiros e universais que se sobrepõem como os legítimos e desejáveis. Nesse sentido, problematizamos a ideia que se produz para o currículo e, ao mesmo tempo, noção que temos sobre os conteúdos escolares. Ao assim proceder, nos dedicamos em problematizar o que tem sido agenciado como conteúdos essenciais em tempos de pandemia, no ambiente domiciliar.

Tendo como referência nossas experiências e nossas pesquisas, afirmamos o currículo como uma linguagem capaz de produzir-se e de produzir diferentes enunciados para o conhecimento e para a aprendizagem. Concordando com Lopes e Macedo (2011)

\begin{abstract}
[...] propomos outra forma de pensar o currículo, não mais como seleção de conteúdos, ou mesmo seleção de cultura, mas como uma produção cultural. O currículo é uma produção cultural por estar nessa luta pelos diferentes significados que conferimos ao mundo. $O$ currículo não é um produto de uma luta fora da escola para significar o conhecimento legítimo, não é uma parte legitimada da cultura que é transportada para a escola, mas é a própria luta pela produção do significado. Assim sendo, não cabe falar em disputa pela seleção de conteúdos, mas disputas na produção de significados na escola (Lopes \& Macedo, 2011, p. 93).
\end{abstract}

Pensar na produção curricular de significados na escola coloca o currículo como linguagem e, sendo linguagem, dizemos que um currículo se comunica, deseja e produz sentidos e significados "para" e "sobre" o conhecimento e a aprendizagem. Desse modo, já nos lançamos a defender a pluralidade de currículos, uma vez que tais enunciados são cultural e politicamente comprometidos com diferentes tendências ontológicas e epistemológicas nas quais se tramam a prática educativa. Nessa direção, as perguntas "o que um currículo quer?" e "o que queremos com os currículos?" não se esgotam, mas se atualizam constantemente em diferentes contextos espaçostemporais. É então desse lugar que emerge uma questão cara a esse trabalho: o que quer um currículo escolar, em tempos de pandemia, no domicílio dos estudantes?

Essa questão requer de nós a produção de algumas paisagens sociais, econômicas e pedagógicas, de maneira a nos auxiliarem em nossos argumentos quando queremos afirmar que currículo escolar na ambiência presencial física não é o mesmo currículo no ambiente remoto emergencial nos domicílios dos estudantes. Como já dissemos na seção anterior, a pandemia aprofundou e tornou ainda mais visíveis as crassas desigualdades socioeconômicas dos estudantes brasileiros. Nesse cenário, os sentidos da escola e das aprendizagens são inumeráveis. A título de exemplo, podemos citar a prova do Exame Nacional do Ensino Médio (ENEM), ocorrida no curso da pandemia, ainda que a maioria das escolas públicas brasileiras estivesse a quase um ano com as auals suspensas. Se para alguns candidatos, originários da rede privada, o exame foi uma abertura para acesso ao ensino superior, para os candidatos da rede pública da Bahia, foi uma das alternativas dadas pela Secretaria de Educação da Bahia (SEC/BA) para a conclusão do ensino médio, uma vez que durante o ano de 2020 as atividades escolares foram suspensas presencialmente e não foram garantidas de maneira remota. Quais os sentidos e significados para diferentes coletivos de estudantes do ensino médio na Bahia? Mas esse exemplo não basta. Precisamos pensar na ambiência domiciliar para onde a escola, provisoriamente, se transportou. Sabemos que muitas crianças e jovens, usuárias do sistema público de educação, residem em construções precárias, 
sejam urbanas ou rurais, com muitas pessoas morando numa mesma residência, em situações de pobreza ou de extrema pobreza. Nesses domicílios, quais as aprendizagens essenciais que devem chegar através dos currículos escolares? Quais os conteúdos escolares se compõem com essas ambiências domiciliares que possam produzir sentidos razoáveis para a escola? Quais as condições materiais e imateriais que os estudantes têm em seus domicílios que favoreçam (ou não) suas aprendizagens escolares?

Estamos, a nosso ver, diante de uma questão ética no sentido da produção curricular quando consideramos a paisagem de pandemia. Não vemos razão na tentativa transpor o currículo escolar para os domicílios dos estudantes, como se somente estivéssemos mudando a "sala de aula" de lugar. Defendemos, nesse veio, a necessidade dos conteúdos escolares definidos nos ementários e programas oficiais serem revisitados, tensionados, (des)construídos. Com isso, não estamos negando o direito ao acesso aos conhecimentos social e historicamente produzidos pela humanidade. Tão somente estamos convidando aos necessários movimentos de problematizações sobre a emergência de outros/novos conteúdos escolares em tempos de pandemia. Estamos diante de impasses dilemáticos em que questões do tipo o que, quando ensinar/aprender e como ensinar/aprender precisam ser tensionados em suas práticas discursivas cujos efeitos se encontram com enunciados que podem estar (e acreditamos que estão) deixando milhares de crianças se jovens excluídos do seu direito de estar na escola (seja no ambiente físico ou virtual) e de aprender.

Entendemos, do nosso lugar de fala e de produção, que o que ora provocamos aqui não é o ensino remoto em si, pois acreditamos que o problema não está na utilização das ferramentas digitais para o desenvolvimento das atividades escolas, mas, a ausência de políticas de assistência e de inclusão sociodigital dos estudantes em paisagens emergenciais. A pandemia é uma zona de passagem, mas as desigualdades educacionais parecem estar sendo estação de pouso.

Ainda na tentativa de avançar nas tensões que envolvem o campo curricular trazemos para tela um outro problema: o discurso do modelo híbrido de escola. Com as tímidas ou ausentes políticas de inclusão digital, temos assistido um apressamento em retornar as aulas presenciais no ambiente físico da escola como uma tentativa de estabelecer uma suposta normalidade. Para nós, esse enunciado está esvaziado de uma discussão mais qualificada e aprofundada no que se refere a um currículo híbrido. Em muitos discursos a defesa está na retomada das atividades sob o argumento do híbrido: atividades na escola e atividades em casa, em sistema de alternância. Os discursos que vão ao encontro de um modelo híbrido que têm emergido no cenário de pandemia deve ser um convite às desconfianças e ao pensamento mais elaborado. Dussel $(2002$, p. 57) já nos advertiu dessa questão e ao assim fazê-lo, fez uma defesa da necessidade de que pensar o currículo em termos de hibridação deve considerar "a complexidade dos processos de produção culturais, políticos e sociais que o configuram [...]". Nessa direção, para a autora,

[...] se deve produzir um 'escrutínio crítico' da noção de hibridação, evitando contentar-se em observar o óbvio e, também, evitando deter o pensamento em uma ingênua celebração da pluralidade e da transgressão, que não se importa com as práticas culturais, políticas e sociais em que se inscreve o hibridismo (Dussel, 2002, p. 57).

Tomando por referência a noção de currículo como linguagem, dizemos que seus enunciados operam "entre" as práticas discursivas. De modo que quando os enunciados defendem "dia na escola", "dia em casa", sob o frágil argumento da mediação pelos tecnologias da informação, nos remete a uma questão que, como nos diz Dussel (2002), nos coloca diante de uma pergunta ética e política: quais as produções de sentido e significado estão em curso para a ideia de um currículo híbrido? Não podemos prescindir dessa questão, que embora não seja motivo desse texto, emerge no rol das problematizações quando perspectivamos pensar os processos formativos em tempos pandêmicos. 


\section{ENSINO REMOTO E APRENDIZAGEM NA PANDEMIA}

A situação educacional que se apresenta na Pandemia da COVId-19 não encontra precedente na história da educação, quer pela abrangência, quer pelos novos formatos de busca e implementação de modelos pedagógicos de oferta educacional. Essa nossa compreensão advém da própria posição da UNESCO, quando afirma que milhares de estudantes que já estavam nas escolas - salvaguardando aqueles que não - devido o fechamento das instituições escolares, estão privados do bem público que é o cotidiano e o conhecimento escolar.

O cotidiano escolar foi, severamente, alterado ou, quando não, submerso às circunstâncias impostas pelas medidas sanitárias, oriundos dos órgãos de saúde pública. Horários, dias letivos, calendário escolar, recesso, férias, semana de provas, conselho de classe foram a ausência do ano escolar de 2020. Esse conjunto de acontecimentos escolares compõe o imaginário pedagógico das escolas e não encontra regramento e aporte para acontecer em outro espaçotempo que não seja a própria escola (presencial). Ezpeleta e Rockwell (1986), em seu clássico A pesquisa participante problematiza a escola como uma complexa trama tecida nesse espaçotempo, como um espaço social próprio, ordenado em dupla dimensão. Assume que essa é constituída de normas e regras, que, além de buscarem unificar ação dos seus sujeitos, orientam a tomada de decisão sobre o agir docente. Nessa cultura escolar, na acepção de Ezpeleta e Rockwell (1986), as relações sociais entre os sujeitos envolvidos, são formadas por alianças e conflitos, imposição de normas e estratégias individuais, ou coletivas, bem como, por meio "de transgressão e de acordos.

A pandemia da Covid-19 nos impõe a criação de uma ambiência pedagógica ainda recente e para que as experiências e vínculos com a instituição escola não sejam tão ou mais fragmentadas, como já se revela. Assim, ao acompanhar os movimentos de redes de ensino para reorganização do calendário escolar e tomada de decisão dos órgãos normativos acerca dos formatos, modelos pedagógicos e arquitetura curricular para validar o direito à educação, um consenso se impôs: a suspensão de aulas presenciais e toda ou qualquer atividade curricular nas escolas. Esse consenso, após inúmeras publicação e republicação de decretos e atos normativos alterando o prazos mobilizou a oferta de ensino remoto, por meio de tecnologias digitais ou outras ferramentas pedagógicas, materializando uma outra composição do regramento escolar, de(des)estabilização das rotinas e rituais de ensino, ante a realização de atividades escolares no domicílio dos estudantes. E, em texto de (Ezpeleta \& Rockwell, 2007), assim concebe sua crítica à escola:

A escola é, na teoria tradicional, uma instituição ou um aparelho do Estado. Tanto na versão positivista (Durkheim), como nas versões críticas (Althusser, Bourdieu), sua pertença ao Estado transforma-a automaticamente em representante unívoca da vontade estatal. A escola tem uma história documentada, geralmente escrita a partir do poder estatal, a qual destaca sua existência homogênea. Nesta interpretação, a escola é difusora de um sistema de valores universais ou dominantes que transmite sem modificação. Na versão positivista, a escola, além de conseguir a inculcação dos valores e normas comuns à sociedade, consegue também a realização dos direitos civis e da justiça social. As versões críticas da escola, baseando-se na própria história documentada, demonstram por sua vez seu caráter reprodutor da ideologia dominante e das relações sociais de produção. Sustentam estas versões, com valoração oposta, o conceito de escola homogeneizante, cuja determinação fundamental é estatal e estrutural.

Coexiste, contudo, com esta história e existência documentada, outra história e existência, não documentada, através da qual a escola toma forma material, ganha vida. Nesta história, a determinação e presença estatal se entrecruza com as determinações e presenças civis de variadas características. A homogeneidade documentada decompõe-se em múltiplas realidades cotidianas. Nesta história não-documentada, nesta dimensãocotidiana, os trabalhadores, os alunos e os pais se apropriam dos subsídios e das prescrições estatais e constroem a escola (Ezpeleta \& Rockwell. p.4. 2007) 
Contudo, o direito à educação nas (trasns)figurações do ambiente doméstico só é possível a partir da composição de uma outra tessitura curricular. Essa tessitura toma a docência e o currículo como linguagem, conforme Souza (2016) e junta-se ao reconhecimento das experiências dos estudantes e sua autonomia de aprendizagem para cumprir plano de aprendizagem.

Assim, propomos analisar a linguagem e as práticas curriculares na escola sob dois planos de significação: o plano rotineiro, compreendido como o cenário da reiteração, repetição, da absolutização do cotidiano, e o plano ritual, assentado em práticas discursivas dialógicas, de resistência e rupturas a o já estabelecido na e pela escola/sujeitos; aparentemente banais, mas que escamoteiam e rompem com cenários homogêneos e autoritários de (re)elaboração de conhecimentos.

É claro que nessa proposta impõe-se considerar o cotidiano escolar com categoria analítica, visto que se apresenta o trabalho com a linguagem na educação e com a educação, por meio dos des(re)velamento de seu plano rotineiro da sala de aula. Compreendemos que ao se olhar para esse rotineiro com o cuidado de não se estabelecer generalizações, chega(re)mos à extração da dialogia dos rituais e das rotinas da sala de aula, possibilitada pela apreensão da movência de interações verbais da aprendizagem, o que, por seu turno, indica uma outra concepção de cotidiano, [...] (Souza, 2016, p.154)

Assim, nova composição de cotidiano escolar encontra-se no terreno doméstico, desde que se abdique o regramento hegemônico e reconheçam-se as possibilidades formativas: o direito à educação escolar na pandemia é dependente da ambiência pedagógica a ser criado no contexto externo à escola. Assim, requereu-se a criação de um "outro cotidiano escolar". Ao fazer essa aposta ética, um novo olhar é lançado sobre questões que se referem aos processos de aprendizagem e formação docente. O ensino remoto emergencial, tomado na acepção de Paiva (2020) é uma pauta que requereu, por parte dos docentes, novas aprendizagens e competências:

Ensino Remoto Emergencial (ERE) como uma mudança temporária da entrega de instruções para um modo de entrega alternativo devido a circunstâncias de crise. Para eles, esse tipo de abordagem envolve o uso de soluções de ensino totalmente remotas para a instrução ou a educação que, de outra forma, seriam ministradas presencialmente ou como cursos combinados ou híbridos, e que retornarão a esse formato assim que a crise ou emergência tiver diminuído (Paiva, 2020, p. 62).

Assim, a configuração do ensino no domicílio dos estudantes recupera e se alia a um conjunto de experiências dos estudantes, exige a realização da docência online ou outros gestos didáticos que se arranjam na consciência da possibilidade da presença, a composição de atividades heterogêneas que criam um currículo praticado por meio do reconhecimento da autonomia do aprender do estudante, como referência a sua trajetória escolar. O corte do cotidiano e da cultura escolar como, hegemonicamente, era o "status" anterior a pandemia, passa por severa desconstrução e requer profundo compromisso ético, por parte dos professores, para materializar essa nova realidade. É claro que a realidade escolar não é idêntica a todos, quer na escola presencial ou no ensino remoto. A ( re) construção da escola, quando a problematizamos com as emergências do cotidiano, nos mobiliza a reconfigurar outras formas de existência material para conhecer e continuarmos os processos formativos.

\section{CONCLUSÃO}

Na pandemia, a ambiência pedagógica se tornou viável por meio da adoção de regimes de oferta da educação mediada por tecnologias. Essa foi a única possibilidade para que, após um período que impactou a todos, as escolas perspectivassem a adoção de modalidades e regimes para 
preservar o vínculo de aprendizagem. Assim, os docentes, com maior ou menor grau, foram instados a participar de formação pedagógica para reconfiguração de suas práticas e os estudantes, por sua vez, se viram imersos em aulas síncronas e assíncronas, quando dispunham de condições para isso, na expectativa de se preservar ou recuperar vínculos com a escola. Para se materializar uma ambiência pedagógica possível, o ensino remoto emergencial foi adotado temporariamente, com mediação pedagógica das tecnologias digitais e não digitais de informação e comunicação.

Essa realidade revelou-se em um novo cotidiano. As nossas representações sobre educação a distância não suportavam os desafios impostos e não colaboravam para esse enfrentamento, vez que todo o planejamento em curso foi para a realização de atividades presenciais e ensino remoto não é transposição. Assim, para mobilizarmos nossas experiências para atender esses desafios, constatamos que o provocar reflexões com coletivo docente e gestores acerca das implicações sobre trabalho docente, currículo e ensino remoto constitui uma tríade que se complementa, pois se faz necessário não dicotomizar o conhecimento produzido no curso da " emergência" para criar um repertório e inventário de práticas pedagógicas que atendam os limites de aprendizagem da realização do ensino remoto como integrante dos currículos escolares. Esperamos ter levantado pontes dialogia para esse debate, com o reconhecimento de que a profissão docente foi e continua sendo produtora de conhecimentos, que rna pandemia, quer na pós-pandemia.

Contribuições dos Autores: Nunes, C. P.: concepção e desenho, aquisição de dados, análise e interpretação dos dados, redação do artigo, revisão crítica relevante do conteúdo intelectual; Raic, D. F. F.: concepção e desenho, aquisição de dados, análise e interpretação dos dados, redação do artigo, revisão crítica relevante do conteúdo intelectual; Souza, E. M. F.: concepção e desenho, aquisição de dados, análise e interpretação dos dados, redação do artigo, revisão crítica relevante do conteúdo intelectual. Todos os autores leram e aprovaram a versão final do manuscrito.

Aprovação Ética: Não aplicável.

Agradecimentos: Não aplicável.

\section{REFERÊNCIAS}

Almeida, M. E. B. (2021). Narrativa das relações entre currículo e cultura digital em tempos de pandemia: uma experiência na pós-graduação. Revista Práxis Educacional, Vitória da Conquista, 17(45), abr./jun. https://doi.org/10.22481/praxisedu.v17i45.8324

Amaral, M. M.; Rossini, T. S. S. \& Santo, E. O. (2021). A viralização da educação online: a aprendizagem para além da pandemia do novo coronavírus. Revista Práxis Educacional, Vitória da Conquista, 17(46), jul./set. https://doi.org/10.22481/praxisedu.v17i46.6825

Antunes, R. (2017). A era das contrarrevoluções e o novo estado de exceção. IN: Lucena, C.; Previtali, F. S. \& Lucena, L. (Org). A crise da democracia brasileira. V. I, Uberlândia: Navegando Publicações.

Bautista-Vallejo, J. M.; Hernández-Carrera, R. M. \& Souza, R. M. (2021). O conhecimento como problema em uma universidade do século XXI. Revista Práxis Educacional, Vitória da Conquista, 17(45), abr./jun.

https://doi.org/10.22481/praxisedu.v17i45.8343

Brasil. (1988). Constituição (1988). Senado Federal. Constituição da República Federativa do Brasil. Texto promulgado em 05 out. 1988. http://www.senado.gov.br

Brasil. (1996). Lei n. 9.394, de 20 de dezembro de 1996. Estabelece as diretrizes e bases da educação nacional. Diário Oficial da União. Brasília, DF: DOU, 1996b.

Brasil. (2008). Lei no 11.738, de 16 de julho de 2008. Regulamenta a alínea "e" do inciso III do caput do art. 60 do Ato das Disposições Constitucionais Transitórias, para instituir o piso salarial profissional nacional para os profissionais do magistério público da educação básica. Diário Oficial da União. Brasília, DF: DOU, 2008b.

Brasil. (2016). Emenda Constitucional no 95 de 15/12/2016. Altera o ato das disposições constitucionais transitórias, para instituir o novo regime fiscal, e dá outras providências. Brasília, Dezembro, 2016.

http://legis.senado.leg.br/legislacao/ListaTextoSigen.action?norma=540698\&id=14374770\&idBinario=15655553\&mi me=application/rtf.n. 
Costa, A. M. F. R.; Almeida, W. C. \& Santos, E. O. (2021). Eventos científicos online: o caso das lives em contexto da COVID-19. Revista Práxis Educacional, Vitória da Conquista, 17(45), abr./jun.

https://doi.org/10.22481/praxisedu.v17i45.8340

Dussel, I. (2002). O currículo híbrido: domesticação ou pluralização das diferenças? In: LOPES, Alice C. \& Macedo, E. (Orgs.). Currículo: debates contemporâneos. São Paulo: Cortez.

Ezpeleta, J. \& Rockwell, E. (1986). Pesquisa participante. São Paulo: Cortez.

Ezpeleta, J. \& Rockwell, E. (2007). A escola: relato de um processo inacabado de construção Currículo sem Fronteiras, 7(2), p.131-147, Jul/Dez. http://www.curriculosemfronteiras.org/vol7iss2articles/rockwell-ezpeleta.pdf

Leite, M. L. S.; Torres, G. G. S. \& Cunha, R. D. T. (2020). Entre sonhos e crises: esquadrinhando os impactos da pandemia por covid-19 na vida de pós-graduandas(os) brasileiras(os). Revista de Estudos em Educação e Diversidade, Vitória da Conquista, 1(2), out./dez. https://doi.org/10.22481/reed.v1i2.7532

Machado, S. S. B. C.; Costa, G. S.; Mallows, D. \& Costa, P. L. S. (2021). Indagações na/com a EJA no contexto de pandemia: uma experiência em círculos de cultura digitais. Revista Práxis Educacional, Vitória da Conquista, 17(45), abr./jun. https://doi.org/10.22481/praxisedu.v17i45.8337

Nobre, A.; Mouraz, A.; Goulão, M. F.; Henriques, S.; Barros, D. \& Moreira, J. A. (2021). Processos de comunicação digital no sistema educativo português em tempos de pandemia. Revista Práxis Educacional, Vitória da Conquista, 17(45), abr./jun. https://doi.org/10.22481/praxisedu.v17i45.8331

Nonato, E. R. S.; Sales, M. V. S. \& Cavalcante, T. R. (2021). Cultura digital e recursos pedagógicos digitais: um panorama da docência na Covid-19. Revista Práxis Educacional, Vitória da Conquista, 17(45), abr./jun. https://doi.org/10.22481/praxisedu.v17i45.8309

Nunes, C. P. (2019). Formación y trabajo docente: cuestiones contemporáneas. Revista Exitus, 9(3), 19-32. https://doi.org/10.24065/2237-9460.2019v9n3ID917

Nunes, C. P. \& Oliveira, D. A. (2017). Trabalho, carreira, desenvolvimento docente e mudança na prática educativa. Educação e Pesquisa, São Paulo, 43(1), p. 65-80. https://www.scielo.br/scielo.php?pid=S151797022017000100066\&script=sci_abstract\&tlng=pt. Acesso em: 11 de maio de 2021.

Paiva, V. L. M. O. (2020). Ensino remoto ou ensino a distância efeitos da pandemia. Estudos Universitários: Revista de Cultura, v. 37(1 e 2), Dez. p. 58-70.

Pesce, L. \& Hessel, A. M. D. G. (2021). Ensino superior no contexto da pandemia da COVID-19: um relato analítico. Revista Práxis Educacional, Vitória da Conquista, 17(45), abr./jun. https://doi.org/10.22481/praxisedu.v17i45.8323

Raic, D. F. F. \& Sá, M. R. G. B. (2021). O retorno a um “novo normal”: a emergência de um pós-normal em educação? Revista Entreideias, Salvador, 10(1), p. 11-37, jan./abr. p. 15-37. https://periodicos.ufba.br/index.php/entreideias/article/view/37982

Ribeiro, J. C. de O. A., Silva, D. O. V. da, Cardoso, E. A. M., \& Nunes, C. P. (2018). A EDUCAÇÃO DO CAMPO EM TEMPOS DE PRIVATIZAÇÃO E GOLPE. Cenas Educacionais, 1(1), 111-128.

https://www.revistas.uneb.br/index.php/cenaseducacionais/article/view/5141

Saviani, D. (2017) A crise política no Brasil, o golpe e o papel da educação na resistência e na transformação. IN: Lucena, C; Previtali, F. S. \& Lucena, L. (Orgs.). A crise da democracia brasileira. Volume I, Uberlândia: Navegando Publicações.

Saviani, D. (2020). Crise estrutural, conjuntura nacional, coronavirus e educação - o desmonte da educação nacional. Revista Exitus, 10(1), e020063. https://doi.org/10.24065/2237-9460.2020v10n1ID1463

Schlemmer, E.; Oliviera, L.C.; \& Menezes, J. (2021). O habitar do ensinar e do aprender em tempos de pandemia e a virtualidade de uma educação OnLIFE. Revista Práxis Educacional, Vitória da Conquista, 17(45), abr./jun. https://doi.org/10.22481/praxisedu.v17i45.8339

Silva, D. O. V. Da; Nunes, C. P. (2021) Políticas públicas como instrumento de valorização docente no Brasil. Revista Ibero-Americana de Estudos em Educação, Araraquara, 16(esp2), p. 1131-1156.

https://doi.org/10.21723/riaee.v16iesp2.14575

Silva, D. O. V.; Brito, V. L. F.; Nunes, C. P. (2019). Valorização docente na conjuntura do pós impeachement de 2016 no Brasil. Revista Cocar (online), Belém, 13(26) p. 1-20, maio/ago.Disponível em: https://periodicos.uepa.br/index.php/cocar/article/view/2518 
Souza, E. M. de F., \& Ferreira, L. G. (2020). Ensino remoto emergencial e o estágio supervisionado nos cursos de licenciatura no cenário da Pandemia COVID 19. Revista Tempos E Espaços Em Educação, 13(32), 1-19.

https://doi.org/10.20952/revtee.v13i32.14290

Souza, E. M. F. (2016). Linguagem e currículo: diálogo com a teoria dialógica. In: Souza, E.M.F. (org). Letramento de Dialogia. Edições UESB. Vitória da Conquista.

Souza, E. M. F. \& Ferreira, L. G. (2021). A matrícula como direito do estudante na pandemia da COVID-19. Revista Práxis Educacional, Vitória da Conquista, 17(44), jan./mar. https://doi.org/10.22481/praxisedu.v17i44.8029

Teixeira, E. C. N. S. \& Nunes, C. P. (2016). O piso salarial como insumo da valorização docente nos governos de FHC e Lula: da política de fundos à Lei do Piso. Revista Práxis Educacional, Vitória da Conquista, 12(23), p. 251-270, set./dez. http://periodicos2.uesb.br/index.php/praxis/article/view/914

Teixeira, E. C. N. S. \& Nunes, C. P. (2019). Os sentidos atribuídos ao piso salarial nacional como política pública de valorização docente. Revista Tempos E Espaços Em Educação, 12(29), 195-212.

https://seer.ufs.br/index.php/revtee/article/view/10688

Teixeira, E. C. N. S. \& Nunes, C. P. (2019). A valorização docente e a lei do piso salarial: um estado da arte. Educação e Cultura Contemporânea, 16(42), p. 437-452. http://periodicos.estacio.br/index.php/reeduc/article/view/1886

Teixeira, E. C. N. S. \& Nunes, C. P. (2019). O Piso Salarial Nacional no Contexto do Financiamento da Educação no Brasil: limites e possibilidades do seu cumprimento. FINEDUCA: Revista de Financiamento da Educação. 9(22), p. 1-17. https://seer.ufrgs.br/fineduca/article/view/90205

Trindade, S. D. \& Santo, E. E. (2021). Competências digitais de docentes universitários em tempos de pandemia: análise da autoavaliação Digcompedu. Revista Práxis Educacional, Vitória da Conquista, 17(45), abr./jun. https://doi.org/10.22481/praxisedu.v17i45.8336

Recebido: 13 de junho de 2021 | Aceito: 25 de julho de 2021 | Publicado: 9 de agosto de 2021

This is an Open Access article distributed under the terms of the Creative Commons Attribution License, which permits unrestricted use, distribution, and reproduction in any medium, provided the original work is properly cited. 